\title{
Comparison of the Effect of Purgative manna and Alhagi Pseudoalhagi Usage on Healing Icterus of neonates
}

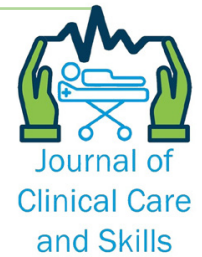

\section{ARTICLE INFO}

\section{Article Type}

Original Research

\section{Authors}

Mohammadi B. ${ }^{1} M D$,

Delavari A. ${ }^{1} M D$

Sadeghi H. ${ }^{1} P h D$

Mohammadi J. ${ }^{* 1} P h D$

\section{How to cite this article}

Mohammadi B, Daliri A, Sadeghi H,

Mohammadi J. Comparison of the Effect of Purgative Manna and Alhagi Pseudoalhagi Usage on Healing Icterus of Infants. Journal of Clinical Care and Skills. 2020;1(2):89-

\section{A B S T RAC T}

Aims Benign neonatal icterus is a common problem in preterm and term neonates. In some countries, traditional medicine is being used to relieve icterus. The aim of this study was to compare the effect of purgative manna and Alhagi pseudoalhagi usage on healing icterus of neonates.

Materials and Methods In this clinical trial, 171 neonates with physiologic icterus that was referred to the Imam Sadjad hospital of Yasuj in 2016, were selected by simple random sampling method and randomly divided into three groups. The control group $(n=57)$ only received phototherapy. The second group $(n=57)$ received 5 oral drops for 3 times per day of purgative manna, and for 3 days along with phototherapy. The third group $(n=57)$ received $1 \mathrm{cc} / \mathrm{kg}$ of a $30 \%$ suspension of Alhagi pseudoalhagi oral drop in each 12 hours for 3 days along with phototherapy. Then the rate of reduction in neonatal bilirubin was compared in the three groups. Data were analyzed by SPSS 21 software using Chi-square, one-way ANOVA, Kruskal-Wallis tests and Tukey's post hoc test.

Findings The Alhagi pseudoalhagi group had lower total bilirubin mean and direct bilirubin mean in comparison to phototherapy and purgative manna groups, and these differences were statistically significant $(\mathrm{p}<0.05)$. Phototherapy and purgative manna had no significant difference $(\mathrm{p}>0.05)$.

Conclusion Regarding the effect of Alhagi pseudoalhagi, its standard products could be used in treatment of icterus in neonates, but purgative manna has no significant effect on the treatment of icterus and is not recommended for icterus treatment.

Keywords Hyperbilirubinemia; Icterus; Alhagi pseudoalhagi; Purgative Manna; Photo‡ therapy
${ }^{1}$ Medicinal Plants Research Center, Yasuj University of Medical Science, Yasuj, Iran

\section{Correspondence}

Address: Physiology Department, Medicine Faculty, Yasuj University of Medical Sciences, Yasuj, Iran. Postal Code: 7591994799 Phone: +98 (74) 3235137 Fax: +98 (74) 3235137 j.mohammadi.4554@gmail.com

\section{Article History}

Received: October 10, 2018

Accepted: : March 11, 2019

ePublished: June 20, 2020

\section{CITATION L I N K S}

[1] Kernicterus and bilirubin encephalopathy [2] Clinical features of bilirubin encephalopathy [3] Nelson textbook of pediatrics e-book [4] Neonatal-perinatal medicine: diseases of the fetus and infant [5] Is Taranjebin a prophylactic agent for neonatal jaundice? J Islamic Repub Iran [6] The effects of oral Manna on reducing neonatal serum bilirubin levels [7] A historical overview of natural products in drug discovery [8] Effects of Taranjebin on serum bilirubin in hyperbilirubinemic suckling rats [9] Study of the effect of Manna Ash on the management of neonatal jaundice [10] Effect of clofibrate in jaundiced term newborns [11] Surveying the effect of cotoneaster spp [12] Effect of Manna from Cotoneaster discolor on infant Jaundice (effect on blood bilirubin level) [13] Efficacy of oral zinc sulfate intake in prevention of neonatal jaundice [14] The effect of herbal drugs on neonatal jaundice [15] Preliminary study of potential toxic effects of taranjebin in Syrian mice [16] The effect of shirkhesht on newborns' indirect hyperbilirobinemia [17] Evaluation of the preventive effects of purgative Manna on neonatal icterus in Sanandaj [18] Effect of shir-e-khesht (billinaster drop) consumption by the neonates or their mothers on the neonatal icter [19] The effect of purgative Manna on the infant jaundice 


\section{Introduction}

Hyperbilirubinemia is a common -mostly benignproblem in neonates $\mathrm{s}$ and is the most common cause of hospitalizing them [1]. The importance of icterus in neonates $s$ is because of its dangerous complications due to bilirubin enhancement in brain that result in severe irreversible mental damages and even death [2].

Approximately $60 \%$ of mature neonates s and $80 \%$ of immature neonates $s$ will be affected by icterus in the first week of life, which its cause is accumulation of non-conjugated, non-polar, and fat-soluble bilirubin pigments in the skin of neonates (indirect reaction). Skin icterus can also be due to the deposition of pigments in the liver microsomes by uridine di-phosphoglucuronic acid glucuronyl transferase enzyme, in the form of Stargolcoronide bilirubin, which is polar and water-soluble [3]. Totally, $6-7 \%$ of mature neonates $s$ have direct bilirubin higher than 12.9 and approximately $3 \%$ of them have indirect bilirubin even higher than $15^{[4]}$.

Crohn's icterus is an encephalopathy of Bilirubin, which appears as a severe neurological syndrome. Most of the affected neonates s will die due to this sever neurological syndrome and those who survive mostly will suffer of complications such as mental disorders, Seizure, Speech and Hearing Disorders, Hypotonia, Extrapiramidal Symptoms, Bilateral Athetose chorea and Muscle Spasm [4]. Crohn's icterus is seen in $1 / 3$ of neonates $s$ with untreated hemolytic disease and bilirubin levels higher than 25-30mg per dl [5].

Phototherapy is the most common therapeutic and prophylactic method for non-conjugated hyperbilirubinemia that almost in all cases will decrease the concentration of bilirubin [6]. Therapeutic effect of phototherapy depends on the energy rate due to effective wave lengths, distance between light and neonates, the skin surfaces exposed by the light, and the speed of hemolysis, metabolism, and secretion of bilirubin [5]. Transfusion of two times higher than present blood volume will be performed in patients that phototherapy could not decrease their high bilirubin level, as well as those that the danger of Crohn's icterus will be higher than performing this procedure ${ }^{[5]}$.

Other therapies are the administration of nonabsorbable materials, which may reduce the serum level of bilirubin and intestinal absorbance of bilirubin, by binding to the bilirubin in the intestine or by reducing the enterohepatic circulation [5]. According to World Health Organization (WHO), $80 \%$ of people still believe in conventional herbal medicines [7]. Row extract of herbs from the past were used as medicine for treatment of several diseases ${ }^{[8]}$,

In several areas of Iran such as Kohgiluyeh and Boyer-Ahmad, Fars, and Lorestan provinces, Alhagi pseudoalhagi is used for treatment of icterus in neonates s. Alhagi pseudoalhagi is one of herbal components that for a long time has been used for treatment of hyperbilirubinemia by Iranian families and Iranian conventional medicine [5]. Alhagi pseudoalhagi is a long lasting plant from Papilionaceae family [3]. This substance may decrease the activity of the beta-glucuronidase enzyme and decrease the intestinal-hepatic circulation and result in more bilirubin to be excreted in the stool [9].

Another herbal component that is widely used in treatment of icterus in neonates $\mathrm{s}$ is purgative manna. Cotoneaster is a white colored substance that is known as purgative manna. The substance is extracted of plants of Cotoneaster SPP genus and Rosaceae family [10]. The most important components of purgative manna are carbohydrates including mannitol, fructose, glucose, and sucrose [11]. It is believed that purgative manna inhibits entering bilirubin into enterohepatic circulation via binding it, and is effective in decreasing icterus ${ }^{[12]}$. The aim of this study was to compare the effect of purgative manna and Alhagi pseudoalhagi usage on healing icterus of neonates s.

\section{Materials and Methods}

The present study was performed as a clinical trial, on neonates $s$ with physiologic icterus that was referred to the Imam Sadjad hospital of Yasuj in 2016. Sampling performed in the simple random manner. The study was conducted on 171 mature neonates s with 2500 to $4000 \mathrm{gr}$ of weight, and 15 to $20 \mathrm{mg} / \mathrm{dl}$ of bilirubin level. Neonates s that needed to blood exchange and also had the clinical signs of sepsis were excluded from the study. Neonates $\mathrm{s}$ that were diagnosed to have icterus were randomly divided into three groups. The first group as the control group $(n=57)$ only received phototherapy. The second group $(n=57)$ received 5 oral drops for 3 times per day of purgative manna (bilinaster produced by Barij esans Company; Kashan), and for 3 days along with phototherapy. The third group $(\mathrm{n}=57)$ received $1 \mathrm{cc} / \mathrm{kg}$ of a $30 \%$ suspension of Alhagi pseudoalhagi (collected from mountains around Yasuj) oral drop in each 12 hours for 3 days along with phototherapy [12]. Then the rate of reduction in neonatal bilirubin was compared in the three groups.

Preparing the extracts of purgative manna and Alhagi pseudoalhagi: After collecting plants, $2000 \mathrm{gr}$ of purgative manna powder and $500 \mathrm{mgr}$ of Alhagi pseudoalhagi were isolated and the desired concentration was prepared. For preparing the extract of purgative manna the bilinaster drop (Barij esans Company; Kashan) was used.

Chi-square test was used for comparing the categorical variables. The normal distribution of 


\section{1}

variabes was evaluated using Kolmogorov-Smirnov test. The one-way ANOVA test was used in case of normal distributed variables; otherwise, KruskalWallis test was used. Tukey's post hoc test was used for comparing groups two by two. Data analysis was done by SPSS 21 software.

\section{Findings}

There was no significant difference among three groups based on gender, age, weight, delivery type, pregnancy age, gravid, and blood groups of mother and neonates ( $\mathrm{p}>0.05$; Table 1$)$.
Mohammadi B. et al.

There was significant difference among three studied groups based on the frequency of total and direct bilirubin levels $(p=0.001$; Table 2$)$.

The means of total $(p=0.001)$ and direct bilirubin $(\mathrm{p}=0.027)$ in three studied groups had significant statistical difference (Table 3).

The Alhagi pseudoalhagi group had lower total bilirubin mean and direct bilirubin mean in comparison to phototherapy and purgative manna groups, and these differences were statistically significant $(\mathrm{p}<0.05)$. Phototherapy and purgative manna groups had similar results and no significant difference was seen between them ( $p>0.05)$.

Table 1) Comparison among 3 studied groups ( $n=57$ in each group) based on frequency of gender, age, weight, delivery type, pregnancy age, gravid, and blood groups of mother and neonates (the numbers in parantheses are percentage)

\begin{tabular}{|c|c|c|c|c|}
\hline Variables/Groups & Phototherapy & Purgative manna & Alhagi pseudoalhagioral & P. value \\
\hline \multicolumn{5}{|l|}{ Gender } \\
\hline Male & $33(57.9)$ & $36(63.2)$ & $31(54.4)$ & \multirow{2}{*}{0.633} \\
\hline Female & $24(42.1)$ & $21(36.8)$ & $26(45.6)$ & \\
\hline \multicolumn{5}{|l|}{ Age (days) } \\
\hline $2-4$ & $31(54.4)$ & $25(43.9)$ & $33(57.9)$ & \multirow{4}{*}{0.707} \\
\hline $4-6$ & $13(22.8)$ & $12(21.0)$ & $12(21.0)$ & \\
\hline $6-8$ & $8(14.0)$ & $12(21.0)$ & $7(12.3)$ & \\
\hline$>8$ & $5(8.8)$ & $8(14.0)$ & $5(8.8)$ & \\
\hline \multicolumn{5}{|l|}{ Weight (gr) } \\
\hline $2500-3000$ & $19(33.3)$ & $15(26.3)$ & $18(31.6)$ & \multirow{5}{*}{0.883} \\
\hline $3000-3500$ & $21(36.8)$ & $24(42.1)$ & $22(38.6)$ & \\
\hline $3500-4000$ & $3(5.3)$ & $8(14.0)$ & $6(10.5)$ & \\
\hline $4000-4500$ & $10(17.5)$ & 7 (12.3) & $8(14.0)$ & \\
\hline$>4500$ & $4(7.0)$ & $3(5.3)$ & $3(5.3)$ & \\
\hline \multicolumn{5}{|l|}{ Delivery type } \\
\hline Cesarean & 35 (61.4) & $38(66.7)$ & $34(59.6)$ & \multirow{2}{*}{0.273} \\
\hline Normal delivery & 22 (38.6) & 19 (33.3) & $23(40.4)$ & \\
\hline \multicolumn{5}{|c|}{ Pregnancy age (weeks) } \\
\hline $36-38$ & $17(29.8)$ & $17(29.8)$ & 25 (43.9) & \multirow{4}{*}{0.275} \\
\hline $38-40$ & $20(35.1)$ & $19(33.3)$ & $20(35.1)$ & \\
\hline $40-42$ & $17(29.8)$ & $19(33.3)$ & $8(14.0)$ & \\
\hline$>44$ & $3(5.3)$ & $2(3.5)$ & $4(7.0)$ & \\
\hline \multicolumn{5}{|l|}{ Gravid } \\
\hline 1 & $12(21.0)$ & $16(28.1)$ & $15(26.3)$ & \multirow{4}{*}{0.980} \\
\hline 2 & $23(40.4)$ & $20(35.1)$ & $22(38.6)$ & \\
\hline 3 & $10(17.5)$ & $11(19.3)$ & $10(17.5)$ & \\
\hline 4 & $12(21.0)$ & $10(17.5)$ & $10(17.5)$ & \\
\hline \multicolumn{5}{|c|}{ Blood groups of mother } \\
\hline $0+$ & $27(47.4)$ & $20(35.1)$ & $25(43.9)$ & \multirow{8}{*}{0.686} \\
\hline $0-$ & $2(3.5)$ & $3(5.3)$ & $2(3.5)$ & \\
\hline $\mathrm{AB}+$ & $9(15.8)$ & $7(12.3)$ & $7(12.3)$ & \\
\hline$A B-$ & 0 & 0 & 0 & \\
\hline A- & $12(21.0)$ & $12(21.0)$ & $11(19.3)$ & \\
\hline$A+$ & 0 & $3(5.3)$ & $1(1.7)$ & \\
\hline B- & $7(12.3)$ & $8(14.0)$ & $9(15.8)$ & \\
\hline $\mathrm{B}+$ & 0 & $4(7.0)$ & $2(3.5)$ & \\
\hline \multicolumn{5}{|c|}{ Blood groups of neonates } \\
\hline $0+$ & $16(28.1)$ & $12(21.0)$ & $12(21.0)$ & \multirow{8}{*}{0.738} \\
\hline $0-$ & $4(7.0)$ & $6(10.5)$ & $6(10.5)$ & \\
\hline $\mathrm{AB}+$ & $5(8.8)$ & $3(5.3)$ & $6(10.5)$ & \\
\hline $\mathrm{AB}-$ & $4(7.0)$ & $3(5.3)$ & $5(8.8)$ & \\
\hline A- & $10(17.5)$ & $18(31.6)$ & $12(21.0)$ & \\
\hline$A+$ & $2(3.5)$ & $1(1.7)$ & $1(1.7)$ & \\
\hline B- & $16(28.1)$ & $11(19.3)$ & $14(24.6)$ & \\
\hline $\mathrm{B}+$ & 0 & $3(5.3)$ & $1(1.7)$ & \\
\hline
\end{tabular}


Table 2) Comparison among three studied groups ( $n=57$ in each group) based on frequency of total and direct bilirubin levels (the numbers in parantheses are percentage)

\begin{tabular}{|c|c|c|c|}
\hline Variables/Groups & Phototherapy & Purgative manna & Alhagi pseudoalhagi \\
\hline \multicolumn{4}{|l|}{ Total bilirubin } \\
\hline $8>$ & $0(0)$ & $2(3.5)$ & $11(19.3)$ \\
\hline $8-9$ & $12(21.1)$ & $12(21.1)$ & $11(19.3)$ \\
\hline $9-10$ & $20(35.1)$ & $26(45.6)$ & $21(36.8)$ \\
\hline $10-11$ & $13(22.8)$ & $14(24.6)$ & $11(19.3)$ \\
\hline $11<$ & $12(21.1)$ & $3(5.3)$ & $3(5.3)$ \\
\hline \multicolumn{4}{|l|}{ Direct bilirubin } \\
\hline$<0.3$ & $7(12.3)$ & $5(8.8)$ & $6(10.5)$ \\
\hline $0.4-0.3$ & $16(28.1)$ & $22(38.6)$ & $25(43.9)$ \\
\hline $0.5-0.4$ & $11(19.3)$ & $11(19.3)$ & $14(24.6)$ \\
\hline $0.6-0.5$ & $4(7)$ & $6(10.5)$ & $2(3.5)$ \\
\hline $0.7-0.6$ & $7(12.3)$ & $8(14)$ & 7 (12.3) \\
\hline $0.8-0.7$ & $6(10.5)$ & $5(8.8)$ & $2(3.5)$ \\
\hline$>0.8$ & $6(10.5)$ & $0(0)$ & $1(1.8)$ \\
\hline
\end{tabular}

Table 3) Comparison of the mean of total and direct bilirubin levels among three studied groups using one-

\begin{tabular}{|c|c|c|c|}
\hline Variables & Mean \pm SD & F. value & P. value \\
\hline \multicolumn{4}{|l|}{ Total bilirubin } \\
\hline $\begin{array}{l}\text { Alhagi pseudoalhagi } \\
\text { group }\end{array}$ & $11.12 \pm 0.36$ & & \\
\hline $\begin{array}{l}\text { Purgative manna } \\
\text { group }\end{array}$ & $14.25 \pm 0.11$ & 0.249 & 0.001 \\
\hline Phototherapy group & $15.25 \pm 0.70$ & & \\
\hline \multicolumn{4}{|l|}{ Direct bilirubin } \\
\hline $\begin{array}{l}\text { Alhagi pseudoalhagi } \\
\text { group }\end{array}$ & $0.69 \pm 0.08$ & & \\
\hline $\begin{array}{l}\text { Purgative manna } \\
\text { group }\end{array}$ & $0.72 \pm 0.16$ & 0.687 & 0.027 \\
\hline Phototherapy group & $0.61 \pm 0.08$ & & \\
\hline
\end{tabular}

\section{Discussion}

Based on the results of the present study, Alhagi pseudoalhagi was more effective in decreasing bilirubin level in comparison to phototherapy and purgative manna, and showed better clinical results. Phototherapy and purgative manna had similar and close results. So, regarding our results and the effect of oral Alhagi pseudoalhagion on reduction of icterus in neonates $\mathrm{s}$, its usage is recommended for treatment of hyperbilirubinemia in neonates $s$.

Results of the studies performed by Tarhani et al. [13], Nabavizadeh et al. [14], and Panjovani et al. [5] showed that Alhagi pseudoalhagi has no effect on prevention of hyperbilirubinemia in full term neonates $\mathrm{s}$, which is in contrast with our results.

Bandegi in his study showed that though Alhagi pseudoalhagi can reduce plasma bilirubin concentration in hyperbilirubinemic mice, the usage of Alhagi pseudoalhagi in human depends on the results of clinical trials [8]. However, Kazorani et al. showed that receiving Alhagi pseudoalhagi with different doses for 10 days, whether oral consumption or intraperitoneal injection, has no significant effect on the serum bilirubin level [15].

Results of this study showed that there is no statistically significant difference between the control (phototherapy) group and the purgative manna group based on the speed of serum bilirubin reduction, and in spite of conventional believe, purgative manna has no effect on decreasing icterus in hospitalized neonates $\mathrm{s}$. This finding is in concordance with the studies performed by Shahfarahat et al. [16] and Mansoori and Ghotbi [17]. On the other hand, in the study of Khoshdel et al. [18] bilirubin level reduction in groups that used bilinaster drop was higher than the control group that was used placebo and phototherapy. So, our results is in contrast with the mentioned study. Azadbakht et al. showed that the speed of bilirubin reduction due to purgative manna drop usage in neonates s that were under phototherapy, was very higher in the first 3 days in comparison to the control group [19], which is also in contrast with our results.

One of the limitations of this study was a small number of samples, which is why the results of the study can not be generalized. Therefore, considering that in Iran this herb is traditionally used in the treatment of neonatal jaundice and also because of the controversial results in reducing neonatal jaundice, it is recommended that supplementary studies be carried out with a larger number of specimens in this regard.

\section{Conclusion}

Regarding the effect of Alhagi pseudoalhagi, its standard products could be used in treatment of icterus in neonates $\mathrm{s}$ via performing supplementary studies. Despite conventional believe that purgative manna is effective on the reduction of icterus in neonates s, its prescribing has no significant effect on the treatment of icterus and is not recommended for icterus treatment.

Acknowledgements: This research is outcome of thesis of student; Azam Daliri, which has been done at Medicinal Plants Research Center of Yasuj University of Medical Sciences. The authors would like to thank Yasuj University of Medical Sciences for support and extending facilities. 
Ethical Permission: The study was approved by ethics committee of Yasuj University of Medical Sciences (Ethic No: IR.YUMS.REC.1395.196).

Conflict of Interests: There is no potential conflict of interest.

Authors' Contribution: Mohammadi B. (First author), Original researcher (25\%); Daliri A. (Second author), Original researcher (25\%); Sadeghi H. (Third author), Methodologist/ Discussion author (25\%); Mohammadi J. (Fourth author), Introduction author/ Statistical analyst (25\%)

Funding: This research was sponsored by Yasuj University of Medical Sciences.

\section{References}

1- Cashore WJ. Kernicterus and bilirubin encephalopathy. Semin Liver Dis. 1988;8(2):163-7.

2- Connolly AM, Volpe JJ. Clinical features of bilirubin encephalopathy. Clin perinatol. 1990;17(2):371-9.

3- Kliegman RM, Behrman RE, Jenson HB, Stanton BM. Nelson textbook of pediatrics e-book. 18 ${ }^{\text {th }}$ Edition. Detroit, Michigan: Elsevier Health Sciences; 2007.

4- Fanaroff AA, Martin RJ. Neonatal-perinatal medicine: diseases of the fetus and neonates . $4^{\text {th }}$ Edition. St. Louis: C.V. Mosby; 1987.

5- Panjvani Z, Kharrazi-Sabet H, Tawakkuli S, Ramazani MR, Sarraf MT. Is Taranjebin a prophylactic agent for neonatal jaundice? J Islamic Repub Iran. 1995;9(1):27-32. 6- Saboute M, Amini L, Kalani M, Valipour NS. The effects of oral Manna on reducing neonatal serum bilirubin levels. J Isfahan Med Sch. 2012;30(185):458-64. [Persian]

7- Dias DA, Urban S, Roessner U. A historical overview of natural products in drug discovery. Metabolites. 2012;2(2):303-36.

8- Bandegi A. Effects of Taranjebin on serum bilirubin in hyperbilirubinemic suckling rats. Koomesh. 2002;3(3):161-6. [Persian]
Mohammadi B. et al.

9- Fayazmoghaddam K, Reshadmanesh N, Kamali Sh. Study of the effect of Manna Ash on the management of neonatal jaundice. Sci J Kurdistan Univ Med Sci. 1999;4(13):20-3. [Persian]

10- Mohammadzadeh A, Farhat ASh, Iranpour R. Effect of clofibrate in jaundiced term newborns. Indian J Pediatr. 2005;72(2):123-6.

11- Ghotbi F, Nahidi Sh, Zangi M. Surveying the effect of cotoneaster spp. (shir khesht) on neonatal jaundice. Res Med. 2007;30(4):347-52. [Persian]

12- Azadbakht M, Pishva N, Mohammadi Samani S, Alinejad F. Effect of Manna from Cotoneaster discolor on neonates Jaundice (effect on blood bilirubin level). J Med Plants. 2005;2(14):36-44. [Persian]

13- Maamouri Gh, Boskabadi H, Mafinejad Sh, Bozorgnia Y, Khakshour A. Efficacy of oral zinc sulfate intake in prevention of neonatal jaundice. Iran J Neonatol. 2014;4(4):11-6.

14- Nabavizadeh Sh, Safari M, Khoshnevisan F. The effect of herbal drugs on neonatal jaundice. Iran J Pediatr. 2005;15(2):133-8. [Persian]

15- Kazerani H, Jamshidian Mojaver M, Yousofinasab A. Preliminary study of potential toxic effects of taranjebin in Syrian mice. Koomesh. 2007;8(2):61-6. [Persian]

16- Shahfarhat A, Mohammadzadeh A, Ramezani M, Amiri M. The effect of shirkhesht on newborns' indirect hyperbilirobinemia. Razi J Med Sci. 2005;12(47):93-8. [Persian]

17- Mansoori M, Ghotbi N. Bahadorbeigi L. Evaluation of the preventive effects of purgative Manna on neonatal icterus in Sanandaj. Sci J Kurdistan Univ Med Sci. 2012;17(2):30-5. [Persian]

18- Khoshdel A, Khayeri S. Effect of shir-e-khesht (billinaster drop) consumption by the neonates or their mothers on the neonatal icter. J Shahrekord Univ Med Sci. 2011:13(4):67-73. [Persian]

19- Azadbakht M, Pishva N, Mohammadi Samani S, Alinejad F. The effect of purgative Manna on the neonates jaundice. Iran J Pharm Sci. 2005;1(2):95-100. 